\title{
CRÍTICA IDEOLÓGICA E DOSTOIÉVSKI ${ }^{1}$
}

http://dx.doi.org/10.11606/issn.2237-1184.v0i26pl33-142

\section{Boris Schnaiderman}

Ao se abordar este tema, surge logo uma pergunta insidiosa, uma verdadeira "pedra no caminho": a crítica ideológica, compreendida como a crítica da ideologia existente numa obra, não será antes problema da história das ideias e não dos estudos literários como tais? As ideias de uma obra não funcionarão simplesmente como "material"? O estudo da literatura não será o estudo da estruturação de todos os elementos, inclusive as ideias, e não o estudo destas propriamente, compreendidas como ideias explícitas ou implícitas? E se eu não dou primazia ao conteúdo numa obra literária, posso acaso iniciar o estudo desta, concentrando-me nos elementos conteudísticos?

Ao mesmo tempo, não é verdade que toda obra é, em essência, ideológica? Mas o fato de geneticamente eu ter sempre um elemento de ideologia afeta por acaso a necessidade de estudar primeiramente todos os elementos intrínsecos de uma obra, na qualidade de "materiais"? Não será importante, mesmo hoje em dia, a afirmação feita em 1936 pelo crítico polonês Manfrede Kridl: "A assim chamada ideologia não tem existência independente numa obra de literatura; não existe nesta da mesma maneira que fora dela, na 'vida', na filosofia ou no jornalismo. Por conseguinte, ela deve ser examinada em sua configuração específica, digamos literária, isto é, em sua função literária"?2

Estas perguntas nos levam, porém, a um campo muito vasto de discussão e, para restringi-lo, vamos colocar de início as dúvidas entre parênteses. E levemos a discussão para o "grosso modo", para a aceitação inicial de conceitos discutíveis, como se fossem válidos, para tentar precisálos depois. É um caminho que parece viável na abordagem de um tema específico, como o nosso.

\footnotetext{
${ }^{1}$ Originalmente publicado em Trans/Form/Ação, vol.1, Marília, 1974.

2 Apud Victor Erlich, Russian Formalism, Haia: Mouton, 1955, p. 159.
}

133|BORIS SCHNAIDERMAN: Rodapé 
Já se escreveu mais de uma vez que a crítica ideológica tem sido importante para ajudar realmente a desvendar o mundo de Dostoiévski, e isto nos coloca diante de um paradoxo: o escritor-ideólogo por excelência tem sido provavelmente o menos apreensível para a crítica munida sobretudo de instrumental ideológico. Existem estudos excelentes sobre a estruturação dos romances de Dostoiévski; a estilística trouxe a sua contribuição importante, mas justamente a crítica ideológica, e no país do próprio escritor, onde este tipo de crítica se tem exercido com a maior intensidade e persistência, debate-se até hoje com o problema que a obra dostoievskiana apresenta sob este ponto de vista.

Será isto uma consequência do fracasso da crítica ideológica como tal? Ou precisamos investigar as condições específicas deste fracasso em relação a Dostoiévski? Parece que, no caso, houve predomínio de análises marcadas por posições ideológicas de momento, a obra do escritor foi utilizada como arma ideológica num ou noutro sentido, e os trabalhos que ajudam a compreender melhor Dostoiévski, inclusive como ideólogo, são aqueles que tratam da ideologia em função da obra em conjunto, enfim, trabalhos que veem nas ideias de Dostoiévski materiais essenciais para a estruturação de seus romances e contos.

Saudado desde a sua primeira obra, o romance Gente Pobre, como o escritor humanista por excelência, um representante da assim chamada Escola Natural russa, com seus "ensaios fisiológicos", que, paralelamente a um caminho seguido no Ocidente, chamavam a atenção para as condições desumanas da vida do povo, Dostoiévski desiludiu muito depressa os que fizeram esta leitura unilateral de sua obra e suscitou a indignação dos que viam na literatura um veículo para o protesto, impossível sob outra forma. Com efeito, para quem procurava na literatura um meio de despertar a consciência moral do povo, ou pelo menos da sua camada mais suscetível a isto, um romance como O Sósia (o segundo que publicou), com a sua ambiguidade fundamental, com a multiplicidade de caminhos que apresenta, e que tornam impossível enquadrá-lo num julgamento unívoco, só podia aparecer como algo monstruoso e disforme, um exemplo de como não se deveria fazer literatura.

E, ao mesmo tempo, para esta crítica, Dostoiévski não podia deixar de constituir um enigma. Poucos escritores tinham a sua sensibilidade para o social, era impossível deixar de reconhecer que os problemas cruciais da Rússia eram por ele escalpelados como jamais se tinha feito. E a par disto, em cada obra, aquela multiplicidade de caminhos, aquele emaranhado de ideologias, sem que o autor dissesse: "O caminho é este". Ou, quando o dizia, colocava na obra um personagem que distorcia aquelas ideias que se conheciam como o credo explícito do escritor, a ponto de tornar muitas 
vezes difícil afirmar o que se pretendia como verdade e o que se apresentava como caricatura.

Se isto provocou polêmicas acirradas em vida do autor, a discussão continuou após a sua morte, sempre havendo uma facção que tomava determinado Dostoiévski, o seu Dostoiévski, como bandeira.

O filósofo V. Solovióv - que, apesar de bem mais jovem que o romancista, chegara a ser um companheiro das suas "andanças místicas" dos últimos anos de vida - deu a tônica de um culto a Dostoiévski, em três discursos proferidos em sua memória. "Os homens de fé criam vida", afirmou, "são aqueles que se denominam sonhadores, utopistas, iurodívie ${ }^{3}$ - são os profetas, os homens verdadeiramente melhores, os dirigentes da humanidade. Estamos hoje aqui para lembrar um destes homens"4.

Não tardou a reação a semelhantes afirmações. N.C . Mikhailóvski, um dos dirigentes da intelectualidade revolucionária russa, publicou o ensaio "Um talento cruel"5, onde se frisam os aspectos de sadismo do romancista e se reconhece a capacidade de Dostoiévski de uma visão profunda da psique humana, visão esta que traz, no entanto, das profundezas o que pode haver de vil, jamais as qualidades dignificantes. $\mathrm{E}$ isto numa época em que os russos precisavam de alguém que lhes mostrasse os caminhos da luta pela verdade e pela justiça.

De modo geral, as duas obras citadas aqui marcaram os poios entre os quais se debateu, com pequenas variações, a crítica dostoievskiana nos anos seguintes. Ora aqui, ora ali, aparecia alguma observação mais interessante, mas de modo geral o esquema bipolar não variou. Os simbolistas russos, aceitaram Dostoiévski como um mestre e precursor, ao lado de Vladimir Solovióv. Com efeito, apesar das origens francesas, o simbolismo russo logo encontrou raízes nacionais para a sua reação ao positivismo, ao naturalismo e ao materialismo vulgar, tão frequentes na literatura dos fins do século passado. Dostoiévski foi apresentado, com insistência, como o Apóstolo, o Profeta, o Vidente. Isto não obstou a que alguns simbolistas chegassem a apontar aspectos realmente importantes de Dostoiévski, como foi sobretudo o caso de Viatchesláv Ivanov, mas de modo geral o romancista passou a ser pretexto para uma pregação irracionalista e palavrosa; os aspectos que hoje parecem mais contingentes de sua obra, particularmente uma visão messiânica da Rússia, que aparece

\footnotetext{
${ }^{3}$ Plural de iurodívi, nome que se dava na Rússia a mendigos insanos, que vagavam pelo país, e aos quais o povo atribuía qualidades de vidente.

${ }^{4}$ V.S. Solovióv, Tri riétchi v pámiat F.M. Dostoiévskovo (Três discursos em memória de F.M. Dostoiévski), Moscou, 1884, Apud N. C. Mikhailóvski, Litieraturno-critítcheskie stafi (Artigos crítico-literários), Moscou, Goslitizdat (Editora Estatal de Obras Literárias), 1957, pp. 641-642. ${ }^{5}$ Jestóki talant, ob. cit., pp. 181-263.
}

135|BORIS SCHNAIDERMAN: Rodapé 
com tanta frequência no Diário de um escritor, foram apresentados como a sua grande mensagem.

Nas décadas de 1910 e 20, era frequente dar-se ênfase às contribuições psicológicas de Dostoiévski. Saíram então dezenas e dezenas de estudos psicanalíticos de sua obra. Com efeito, para quem tenha penetrado no mundo do escritor, é surpreendente a sua visão aguda neste sentido. Torna-se quase inacreditável, por exemplo, que certas páginas de Niétotchka Niezvánova, com sua visão clara do erotismo infantil, ou conto como O pequeno herói, tenham sido escritos muito antes da existência de Freud. A penetração que Dostoiévski faz no mundo dos sonhos e das fantasias é outra faceta que o aproxima surpreendentemente da psicanálise. Não importa que alguns tenham procurado em obras anteriores a raiz de semelhante argúcia no trato destas questões. Mesmo fazendo-se apelo a E.T.A. Hoffmann e à literatura popular, continua surpreendente a visão aguda de Dostoiévski. Mas, apesar disto, parece magra a contribuição da crítica psicanalítica para a compreensão de sua obra. E o próprio ensaio freudiano, "Dostoiévski e o parricídio"6, se apresenta considerável interesse para o conhecimento da psicanálise, pouco acrescenta para um compreensão real do escritor. Depois de tanta insistência na "psicologia de Dostoiévski", soou muito oportuna a advertência de Adorno em suas Notas de literatura: "... na medida em que há nele psicologia, trata-se de uma psicologia de natureza inteligível, de essência, e não dos homens empíricos, tais como os que se movem no mundo"7. Portanto, com toda a sua agudeza psicológica, Dostoiévski é, antes de tudo, o escritor que dá corpo e voz às ideias, que faz viver, em carne e sangue, o inteligível. Mais uma vez coloca-se a questão, e com mais força depois de Adorno: como se tornou possível que a crítica ideológica fosse a menos capaz de compreendê-lo? O problema é candente, mas, para tentar explicá-lo, temos de continuar a investigar, ainda que sumariamente, as condições em que ela trabalhou.

É verdade que várias obras marcadas pelas limitações da crítica ideológica da época (e a crítica que propunha a psicologia como fundamento de qualquer análise, e não apenas num setor bem delimitado, como Freud operou em seu famoso artigo, parece ser realmente ideológica), apresentaram, ao mesmo tempo, graças à qualidade de seus autores, alguns elementos valiosos para a compreensão de Dostoiévski. Foi sem dúvida o que aconteceu com o livro de Gide ${ }^{8}$.

\footnotetext{
6 Tradução inglesa: "Dostoievsky and Parricide", in Sigmund Freud, Collected Papers, Vol. V, Londres: Hogarth Press, 1953.

7 Theodor W. Adorno. Notas de literatura. Barcelona: Ediciones Ariel, 1962, p.47.

8 André Gide. Dostoïevski. Paris: Gallimard, 1970. Primeira edição: Pion, 1923, mas parte dos materiais do livro data de 1908.
} 
Não é por acaso que ele vem sendo reeditado até hoje. Se nele encontramos generalizações ridículas sobre o "espírito russo"; se, embora a partir da p. 169, ele se volte contra a tendência francesa de reduzir tudo a uma fórmula e ver em Dostoiévski apenas a "religião do sofrimento", Gide não consegue deixar de pagar seu tributo a esta visão da obra dostoievskiana, chegando a supor que um espírito orgulhoso jamais compreenderia o escritor russo (p. 80); se com frequência demasiada sentese aquilo que ele declara explicitamente, em relação a Dostoiévski - que na obra deste procurou, como as abelhas de Montaigne, aquilo que mais convinha ao seu mel (p. 206); quantas formulações de seu livrinho precioso são uma verdadeira antevisão do que a crítica dostoievskiana mais recente vem explorando: a complexidade do mundo criado pelo escritor russo, a impossibilidade de enquadrar sua obra numa ideologia determinada, a polivalência e pluralidade de tudo o que saiu de sua pena etc...

A Revolução de Outubro, que foi acompanhada de tão grandes transformações em toda a vida cultural russa, provocou também uma reviravolta nos estudos dostoievskianos. De início, percebe-se com frequência certa perplexidade. Aquelas contradições na vida e na obra, aquele martirológico revolucionário e uma atuação muitas vezes reacionária, como explicar tudo aquilo?

Um documento conservado no Museu-residência F. M. Dostoiévski, em Moscou, o "Atestado n. ${ }^{\circ}$ 626", reflete bem esta desorientação. Fornecido à dvoriank $a^{9}$ Iecatierina Pietrovna Dostoiévskaia, afirma que ela é "esposa de Fiódor Fiódorovitch Dostoiévski, filho do famoso escritor russo Fiódor Mikháilovitch, velho revolucionário, preso em 1849, no reinado do czar Nicolai Pávlovitch, devido a manifestação 'criminosa' contra o regime imperial e histórico, ao lado de outros revolucionários, e que foi condenado à morte por fuzilamento. Já no local da execução, no momento de ser dada ordem de atirar, a sentença foi atenuada. Condenaram Fiódor Mikháilovitch Dostoiévski a quatro anos de trabalhos forçados. Faleceu em 1881, no dia 28 de janeiro, levando consigo um ativo defensor dos desvalidos, mas deixando-nos seus inapreciáveis trabalhos, tão necessários para a ulterior reeducação da humanidade. Respeitando profundamente a memória do camarada F. M. Dostoiévski, pedimos não causar dificuldades a seus parentes diretos, os netos, rebentos do lutador pela liberdade dos homens"10.

Transcrevendo o documento, o autor da comunicação publicada em Vopróssi litieratúri não esconde um sorriso de ironia diante de tão

\footnotetext{
${ }^{9}$ Mulher de condição nobre. Embora datado de 5 de maio de 1919 e tendo o carimbo do Comitê Executivo dos Deputados Operários, Camponeses e do Exército Vermelho, da cidade de Sadovsk, do governo da Táurida (Criméia), o documento ainda utiliza este termo.

${ }^{10}$ Segundo nota informativa de G. Kógan, diretor do Museu-residência de F. M. Dostoiévski de Moscou, publicada em Vopróssilitieratúri (Problemas de literatura), no 3 de 1965, pp. 252-253.
}

137|BORIS SCHNAIDERMAN: Rodapé 
estrambótico atestado. Mas, ao mesmo tempo, é o caso de se perguntar: a lembrança do destino estranho de Dostoiévski, dos anos passados na Casa dos Mortos e, sobretudo, daqueles momentos diante do pelotão de fuzilamento, não terá contribuído, num nível mais elevado, para o grande interesse por Dostoiévski nos anos que se seguiram à Revolução?

Publicaram-se então materiais importantíssimos que estavam inéditos. Alguns deles são absolutamente indispensáveis para um conhecimento adequado de Dostoiévski. Por exemplo, o capítulo que fora excluído de Os demônios pelo próprio escritor, aquele episódio em que Stavróguin, depois de ter violentado uma garotinha, aguarda quieto o suicídio desta por enforcamento, lança uma luz violenta e diferente sobre o romance todo, este fica muito mais uno e estruturado.

Paralelamente, foram saindo estudos importantes sobre a obra do escritor. O que se fez então foi tão importante que permitiu a D.S. Mirsky afirmar, em 1931, no prefácio ao livro de Edward Hallett Carr sobre Dostoiévski, que tudo o que se fizera no campo, antes de 1921, se tornara mais ou menos obsoleto ${ }^{11}$.

Já nos primeiros anos após a Revolução, começaram a sair os importantes estudos de Leonid Grossman, que culminaram em seu livro de 1925, A Poética de Dostoiévski. ${ }^{12}$ Nesta obra, Grossman estuda o estilo e a construção de Dostoiévski e proclama, ao contrário das afirmações tão correntes de que ele "escrevia mal" e tinha "estilo pesado", que foi sobretudo um grande artista e que era um absurdo deixar de lado este aspecto essencial de sua obra, a fim de procurar nela apenas a psicologia e a filosofia. Trata-se de um estudo realmente magistral que não teve a justa repercussão no Ocidente devido em grande parte às dificuldades que passaram a surgir pouco depois na União Soviética, para a divulgação das obras consideradas formalistas. O estudo foi mais tarde refundido, sobretudo no sentido da maior articulação dos elementos estéticos com uma visão histórica do fenômeno literário, sendo publicado com o título de "Dostoiévski artista" na coletânea com que a Academia de Ciências assinalou o reinício na U.R.S.S., em âmbito oficial, de estudos sérios da obra de Dostoiévski13.

Na década de 1920, surgiram outros estudos fundamentais para uma compreensão da obra do romancista. Os dois mais importantes situam-se no campo oposto ao de uma crítica estritamente ideológica. Em Problemas

\footnotetext{
${ }^{11}$ Edwar Hallett Carr, Dostoievsky, Londres, Allen \& Unwin Ltd. 1931.

12 Leonid Grossman, Poética Dostoiévskovo, publicação da Academia Estatal de Ciências da Arte, Moscou, 1925.

${ }^{13}$ Leonid Grossman, "Dostoiévski - khudójni", In: Tvórtchestvo F. M. Dostoiévskovo (A obra de F. M. Dostoiévski) Moscou: 1959. Traduzido por mim para o português: Dostoiévski artista, Rio de Janeiro: Ed. Civilização Brasileira S.A., 1967.
}

138|BORIS SCHNAIDERMAN: Rodapé 
da obra de Dostoiévski, Mikhail Bakhtin ${ }^{14}$ expõe sua concepção do romance polifónico (do qual Dostoiévski seria o representante mais completo), isto é, o romance em que não há uma voz bem definida que articule tudo, de acordo com as concepções ideológicas do autor, mas aparece multiplicidade de vozes, cada personagem expõe sua ideologia, sem que uma delas prevaleça sobre as demais, o que se reflete em todos os níveis da obra, desde os macro até os microelementos. Iúri Tinianov publicou seu importante ensaio "Dostoiévski e Gógol - Para a teoria da paródia"15, onde se destacam os elementos parodísticos da obra de Dostoiévski e se mostra como os personagens dostoievskianos, muitas vezes, não existem apenas como tais, como indivíduos definidos psicologicamente, mas remetem a outro texto, falam por alusões, enfim, trazem à tona um mundo muito mais rico que a mera reprodução da realidade empírica imediata.

Obras como estas abrem caminhos novos para a compreensão de Dostoiévski e permitem a exploração em inúmeras direções. Uma crítica ideológica que parta da constatação desta complexidade essencial do romancista russo, que assimile os elementos fornecidos por Grossman, Bakhtin e Tinianov, ainda tem muito a nos dizer. No entanto, estes caminhos já delineados têm sido trilhados poucas vezes, e poucas vezes também os resultados obtidos estão à altura das premissas colocadas tão agudamente por estes trabalhos iniciados na década de 1920.

Com o ostracismo em que caiu o movimento formalista russo e as perseguições que atingiram todos os que tiveram algum contato com ele (mesmo os que não o aceitaram e procuraram discutir criticamente, mas com elevação, os seus trabalhos), todos os estudos literários russos sofreram tremendo retrocesso.

Quanto aos estudos dostoievskianos, isto se refletiu numa tendência de aceitar como indiscutível a concepção de que Dostoiévski foi um grande escritor, mas cuja obra se ressente do reacionarismo de suas concepções políticas. As contradições que marcam tudo o que deixou seriam responsáveis por debilidades inclusive de ordem literária. Assim, por exemplo, no $1 .^{\circ}$ volume do Dicionário Enciclopédico, publicado em 1953 pela Grande Enciclopédia Soviética, lê-se no verbete sobre o escritor: "Nos romances de Dostoiévski se refletem, por vezes com doentia agudez, algumas contradições da vida social no período da instauração do capitalismo na Rússia. No entanto, a visão de mundo falsa e reacionária limitava as possibilidades artísticas de Dostoiévski e determinou sua influência negativa sobre alguns escritores russos e estrangeiros". O conceito exposto neste verbete anônimo encontra-se em numerosos

\footnotetext{
14 Problêmi toórtchestva Dostoiévskovo. Foi refundido e saiu em 1963 com o título de Problêmi poétiki Dostoiévskovo (Problemas da Poética de Dostoiévski).

15 "Dostoiévski i Gógol (k teórii paródii)", in Arkhaísti i novátori, Leningrado, 1929, obra reimpressa pela Wilheim Fink Verlag de Munique, em 1967.
}

139|BORIS SCHNAIDERMAN: Rodapé 
artigos, ensaios, histórias da literatura e mesmo livros com ambição teórica, que se publicaram no período estalinista. Depois de 1956, quando ocorreu certa liberalização da vida cultural, muitos estudiosos se voltaram para a obra de Dostoiévski, tentando uma abordagem que não estivesse viciada por este viés unilateral, e a crítica mais dogmática atacou essas tentativas, sempre na base do mesmo chavão. A coletânea publicada em 1959 pela Academia de Ciências, e à qual já me referi, constituiu um passo importante para se tornar a estudar Dostoiévski com toda a seriedade. Desde então, revistas e publicações especializadas soviéticas têm divulgado interessantes materiais sobre ele.

Mas a crítica ideológica, em sentido estrito, continua a manifestar-se de modo tal que a obra dostoievskiana parece apenas um elemento utilizado a favor desta ou daquela posição de momento. Recentemente, provocou, grande escândalo a publicação de um artigo de A. Mazurkévitch ${ }^{16}$, onde Dostoiévski aparece como alguém que "pregava a submissão impotente, uma resignação de escravo e um auto sacrifício obtuso" e, ao mesmo tempo, 'enxertava na literatura instintos zoológicos" e até "estimulava as chagas do capitalismo". Na imprensa soviética, diversos comentaristas voltaram-se indignados contra esta manifestação extremada do "sociologismo vulgar", tão frequente nas décadas de 1920 e 30 , e sobretudo estranharam que semelhante trabalho tivesse encontrado abrigo numa coletânea destinada a professores secundários, aos quais o guia improvisado chega a aconselhar que não "deem muito lugar aos textos" de Dostoiévski em suas aulas.

Houve uma verdadeira onda de artigos em que se procurava combater a apresentação dualista de Dostoiévski como um ficcionista genial e, ao mesmo tempo, um pensador reacionário. Teve grande repercussão um artigo de $\mathrm{M}$. Khráptchenko, em que este dizia: "A opinião de que a concepção de mundo do escritor, em todas as suas manifestações essenciais, era conservadora, não corresponde à realidade"17.

O livro de Augusto Vidal sobre Dostoiévski, publicado na Espanha ${ }^{18}$, encontrou repercussão muito favorável na Rússia. "Podemos acaso contentar-nos com afirmar: Dostoiévski foi reacionário e obscurantista? Nós respondemos a esta pergunta com outra: será justo ceder Dostoiévski à reação?" E estas perguntas do ensaísta espanhol condizem bem com o clima que se criou na Rússia em torno de Dostoiévski.

\footnotetext{
16 A. Mazurkévitch, "Problemas da preparação metodológica do professor para um estudo panorâmico da obra de F. M. Dostoiévski", na coletânea Povichênie vospitáüelnoi róli litleratúri (Elevação do papel educativo da literatura), Kiev, 1972. Minhas citações baseiam-sem em resenhas e comentários sobre o artigo, publicados em 1973 na revista Vopróssi litieratúri.

17 M. Khráptchenko, Dostoïevski $i$ ievó litieratúrnoie nasliédie (Dostoiévski e sua herança literária), Comunista1971, N. ${ }^{\circ}$ 16, p. 109 (minha citação é indireta). O órgão em que o trabalho foi publicado influiu provavelmente na grande repercussão do artigo.

18 Augusto Vidal, Dostoiévski, Barcelona, Barral Editores, 1972.
}

140|BORIS SCHNAIDERMAN: Rodapé 
É verdade que este escreveu contra o socialismo e o movimento revolucionário russo em geral. Agora aparecem, porém, numerosos articulistas que lembram: mas que socialismo era aquele? Na realidade afirmam eles, Dostoiévski se voltava contra o socialismo pequeno-burguês, o positivismo estreito e o extremismo anarquista, tão frequente na Rússia de seu tempo. E este extremismo anarquista é aproximado das atuais tendências de extrema-esquerda, da contracultura e do maoísmo da juventude ocidental, de modo que, de inimigo, Dostoiévski passa a aliado, na luta justa e na posição considerada correta no momento. Como uma das consequências desta nova posição, ocorreu fatalmente uma valorização de Os demônios, romance que durante muitos anos foi considerado um panfleto contrarrevolucionário, indigno de um verdadeiro artista. Este entusiasmo por uma revisão da obra dostoievskiana chegou a tal ponto que I. Kariákin definiu o romancista como "objetivamente, um aliado do marxismo"19, mas semelhante exagero encontrou os seus críticos.

Aonde nos pode levar esta nova concepção da obra de Dostoiévski? Se a visão dualista de um grande escritor, apesar de suas contradições e sua concepção reacionária, sem um exame aprofundado destas contradições, era bem simplificadora, não é menos simplista a visão que nos apresentam agora. Diante dela, como explicar certas páginas do Diário de um escritor, caracterizadas por um chauvinismo grão-russo simplesmente intolerável à leitura e repassadas de ódio ora ao ocidental em geral, ora ao judeu, ora a outras populações do Império? Como harmonizar um Dostoiévski "positivo" politicamente, com a sua visão messiânica da Rússia? Quanto mais a crítica engajada em posições políticas de momento se dedica ao escritor, em busca de um aliado, menos compreensíveis se tornam certos aspectos de sua obra. Não será o caso de a própria crítica ideológica explorar, em seu campo específico, as novas possibilidades abertas pelos importantes estudos russos que têm aparecido a partir da década de 1920?

Chegando a este ponto, ressurgem as dúvidas iniciais. Estamos tratando de "crítica ideológica", mas não chegamos a definir o seu campo de ação, e o próprio emprego do conceito não ficou muito claro. E, mais uma vez, aparece a pergunta: serão as ideias simples materiais? Comentando a concepção de "material" dos formalistas russos, o teórico polonês Manfred Kridl, já citado, e que acompanhou os trabalhos daquele movimento com simpatia e espírito crítico, lembra que, se realmente a obra literária resulta da estruturação de "materiais", estes não são materiais inertes e sim matéria viva, o que implica obrigatoriamente uma dialética entre a estruturação da obra e os materiais nela empregados. E esta

\footnotetext{
${ }^{19}$ Num artigo na revista Naúka i relíguia (Ciência e Religião), no 10 de 1971, citado por I. Seleznióv em "Postigaia Dostoiévskovo" (Apreendendo Dostoiévski), Vopróssi litieratúri, N. ${ }^{\circ} 8$ de 1973, p. 224.
}

141|BORIS SCHNAIDERMAN: Rodapé 
formulação, que se aproxima da visão que Iúri Tinianov e Roman Jakobson expressaram em fins da década de 1920, nos coloca diante de um problema complexo. Ideias são matérias, porém materiais vivos, e como tais devem ser tratadas. E o estudo literário é um estudo da estruturação das obras, que é um processo multiforme, variegado, de contornos imprecisos, devido à própria natureza do "material".

Nada disso, porém, anula a diretriz traçada há pouco, de que nenhum estudo "ideológico" da obra de Dostoiévski pode deixar de se apoiar nos resultados alcançados pelos trabalhos de Tinianov, Grossman e Bakhtin. Como fazer isto? Novas perguntas somam-se às iniciais. No caso, convém lembrar uma formulação de Iúri Lotman; em seu último livro afirma que os estudos literários antes se apressavam a responder e hoje estão aprendendo a perguntar ${ }^{20}$.

Mas, de indagação em indagação, a imagem de Dostoiévski, a princípio recortada grosseiramente em branco e preto, vai se colorindo de matizes cada vez mais opulentos e variados, cada vez mais fascinantes em suas contradições e esfumaçamento.

20 Iúri Lotman, Análiz poetítcheskovo teksta (Análise do texto poético), Leningrado, Editora Prosviechchênie (Instrução), 1972, p. 6. 